\title{
Erosive Pustular Dermatosis of the Scalp: Why Do We Miss It?
}

\author{
Vincenzo Piccolo ${ }^{a}$ Teresa Russo $^{a}$ Stephanie Bianco ${ }^{b}$ Andrea Ronchic \\ Roberto Alfano ${ }^{d}$ Giuseppe Argenziano ${ }^{a}$ \\ ${ }^{a}$ Dermatology Unit, University of Campania Luigi Vanvitelli, Naples, Italy; ${ }^{b}$ Gamboa Hospital, Rio de Janeiro, Brazil; \\ 'Anatomic Pathology Unit, University of Campania Luigi Vanvitelli, Naples, Italy; ${ }^{d}$ Department of Anesthesiology, \\ Surgery and Emergency, University of Campania Luigi Vanvitelli, Naples, Italy
}

\section{Keywords}

Erosive pustular dermatosis of the scalp · Dermoscopy ·

Thricoscopy · Misdiagnosis · Squamous cell carcinoma .

Basal cell carcinoma

\begin{abstract}
Erosive pustular dermatosis of the scalp (EPDS) is an uncommon disease and primarily affects older men who have photo-damaged bald scalp, as was confirmed by our case series. EPDS is probably an overlooked disease, whose diagnosis is often missed because of a higher incidence of other cutaneous diseases affecting the same area and usually secondary to chronic actinic damage, such as actinic keratosis, basal cell carcinoma, and squamous cell carcinoma. For the first time, we report a case series of misdiagnosed EPDS with the aim of understanding why a diagnosis of EPDS was initially missed and try to give some tips to avoid future diagnostic delay.
\end{abstract}

๑) 2019 S. Karger AG, Basel

\section{Introduction}

Erosive pustular dermatosis of the scalp (EPDS) is a rare, inflammatory, and chronic slow-onset disease that causes scarring alopecia and mainly affects the scalp of older men. First described in 1977 by Burton [1], it can occasionally appear on the legs in patients with venous hypertension and atrophic skin [2]. Clinical diagnosis could be challenging since it mimics more common diseases and due to its nonspecific clinical features. At histology, different findings can be seen depending on the stage of disease, with EPDS potentially being characterized by atrophic epidermis and chronic inflammation consisting of lymphocytes, neutrophils, and occasional foreign body giant cells [3]. Dermoscopy (or trichoscopy) has been recently reported as a useful aid for the diagnosis, as it shows absent follicular ostia with marked skin atrophy, with consequent visualization of dermal vessels, although histology is mandatory for the final diagnosis. Herein we report clinical features of 8 patients affected by EPDS, whose diagnosis was initially wrong, and discuss the reasons which led to diagnostic mistakes.

\section{Materials and Methods}

We retrospectively collected information about the history and clinical and trichoscopic features (when present) of patients affected by histologically proven EPDS, whose first diagnosis was different from EPDS. Only patients with high-quality clinical pictures were included in the study. Patients whose diagnosis was correctly made from the beginning were excluded from our evalua-

\section{KARGER}

(c) 2019 S. Karger AG, Basel

E-Mail karger@karger.com

www.karger.com/drm
Vincenzo Piccolo, MD

c/o II Policlinico, Edificio 9, Primo piano

Via Pansini 5

IT-80131 Naples (Italy)

E-Mail piccolo.vincenzo@gmail.com 
Table 1. Patient features

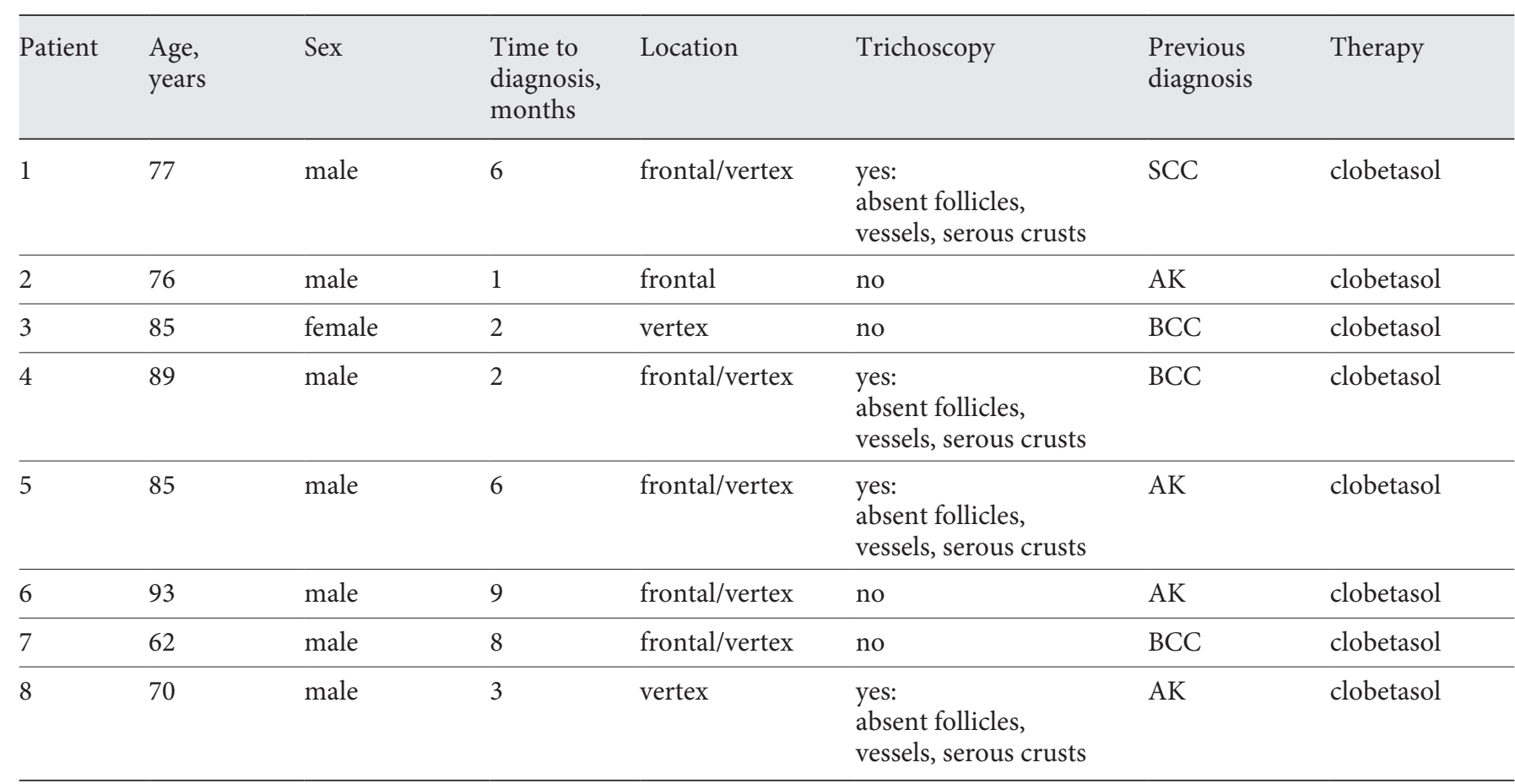

tion. Data regarding sex, age at diagnosis, time to diagnosis, first diagnosis, location of cutaneous lesions, dermoscopic/trichoscopic findings (when available), therapeutic strategy, and likely inducing factor were collected.

\section{Results}

We retrospectively extracted from our database the records of 8 patients affected by histologically proven EPDS, whose diagnosis was missed at the initial evaluation. All patients' features are summarized in Table 1. Most patients $(7 / 8)$ were males with age at diagnosis ranging from 62 to 93 years (mean: 79.6 years). Time to diagnosis ranged from 1 to 9 months (mean: 4.6 months). All patients presented with active disease (erosions and crusts) located on the frontal/vertex area in 5 cases, the vertex area alone in 2 cases, and the frontal area alone in 1 case. Trichoscopic features were available in half of the cases, all presenting with absence of follicular ostia, dilated vessels, and perifollicular serous crusts. The most common wrong initial diagnosis was actinic keratosis (AK) in 4 patients, followed by basal cell carcinoma (BCC) in 3 patients, and squamous cell carcinoma (SCC) in 1 case. Most patients (7/8) were previously treated with topical

Erosive Pustular Dermatosis of the Scalp:

Why Do We Miss It? imiquimod and/or cryotherapy with progressive worsening of cutaneous lesions. Histopathology was obtained in all patients and showed absence of follicles, mixed inflammatory infiltrate, and dermal fibrosis as constant features

After histological confirmation, all the patients underwent topical corticosteroid treatment with quick response after 2 weeks. After a 3-month follow-up no patients recurred except one. Some of the clinical features of the patients are presented in Figures 1-4.

\section{Discussion}

EPDS is an uncommon disease and primarily affects older men who have photo-damaged bald scalp, as was confirmed by our case series. It is usually characterized by the association of pustules, erosions, and serous/hemorrhagic crusts appearing on atrophic skin. Its diagnosis is difficult and poorly considered by clinicians, because of aspecific clinical, dermoscopic and histopathologic features. As EPDS is a diagnosis of exclusion, many diseases should be considered in differential diagnosis, including common eczema and pyodermitis, skin cancer, and rarer diseases such as pustular psoriasis, cicatricial pemphigoid, and pyoderma gangrenosum. Table 2 presents fea- 

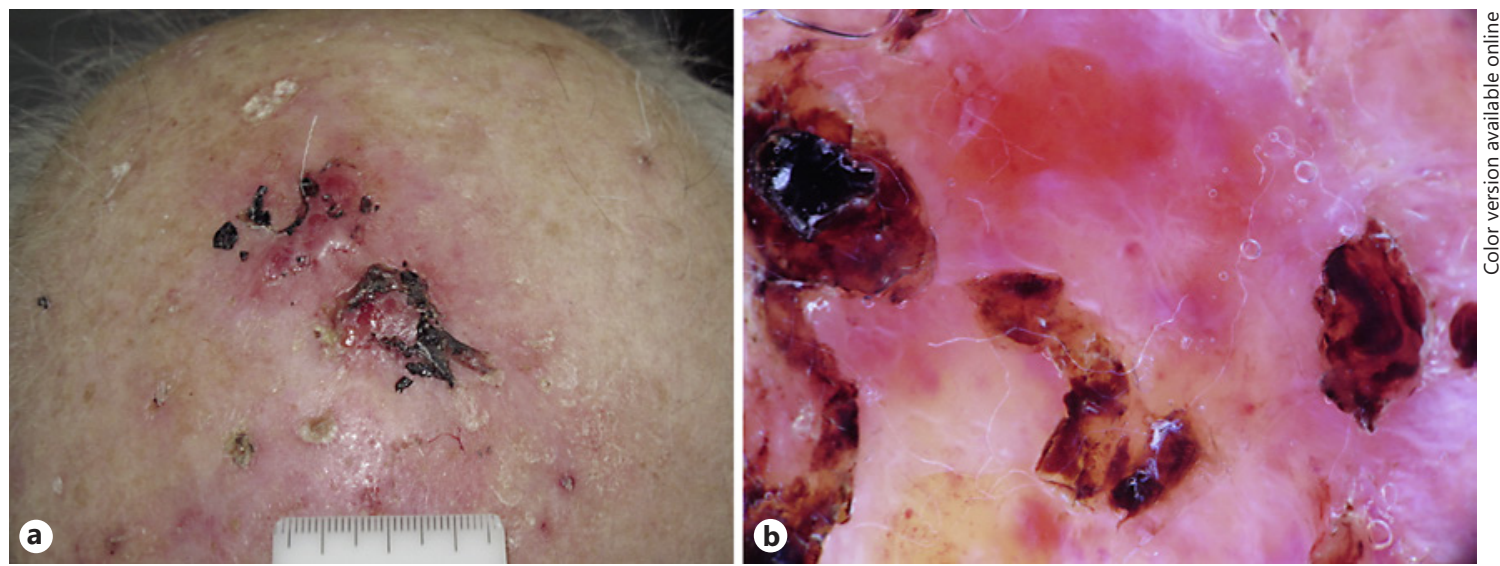

Fig. 1. a Clinical features of patient 1 showing erythematous and crusted vegetant lesions of the scalp. b Dermoscopy revealed absence of follicles, vessels, and serous crusts.

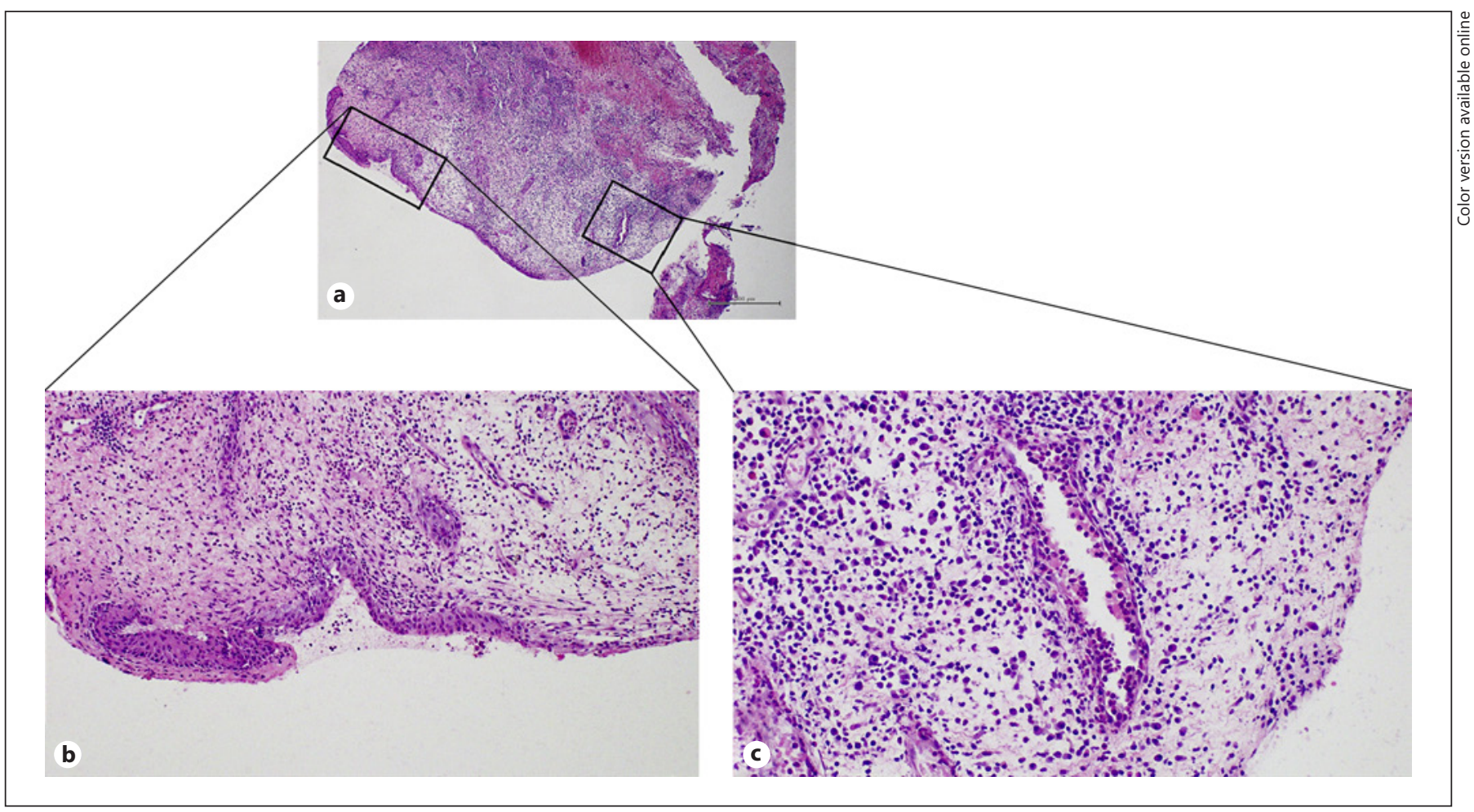

Fig. 2. a Microscopic examination showed a dense inflammation within the epidermis and dermis. H\&E. $\times 2.4$. b The epidermis showed thinning and erosion, and the superficial dermis was strongly edematous. H\&E. $\times 10$. c The inflammatory population was composed of lymphocytes, plasma cells, neutrophils, and eosinophils. H\&E. $\times 20$.

tures of main diseases in differential diagnosis and provides essential clues for each condition. EPDS is probably an overlooked disease, whose diagnosis is often missed because of a higher incidence of other cutaneous diseases affecting the same area and usually secondary to chronic actinic damage, such as AKs, BCC, and SCC. For the first time, we report a case series of misdiagnosed EPDS with the aim of understanding why a diagnosis of EPDS was initially missed and try to give some tips to avoid future diagnostic delay. 

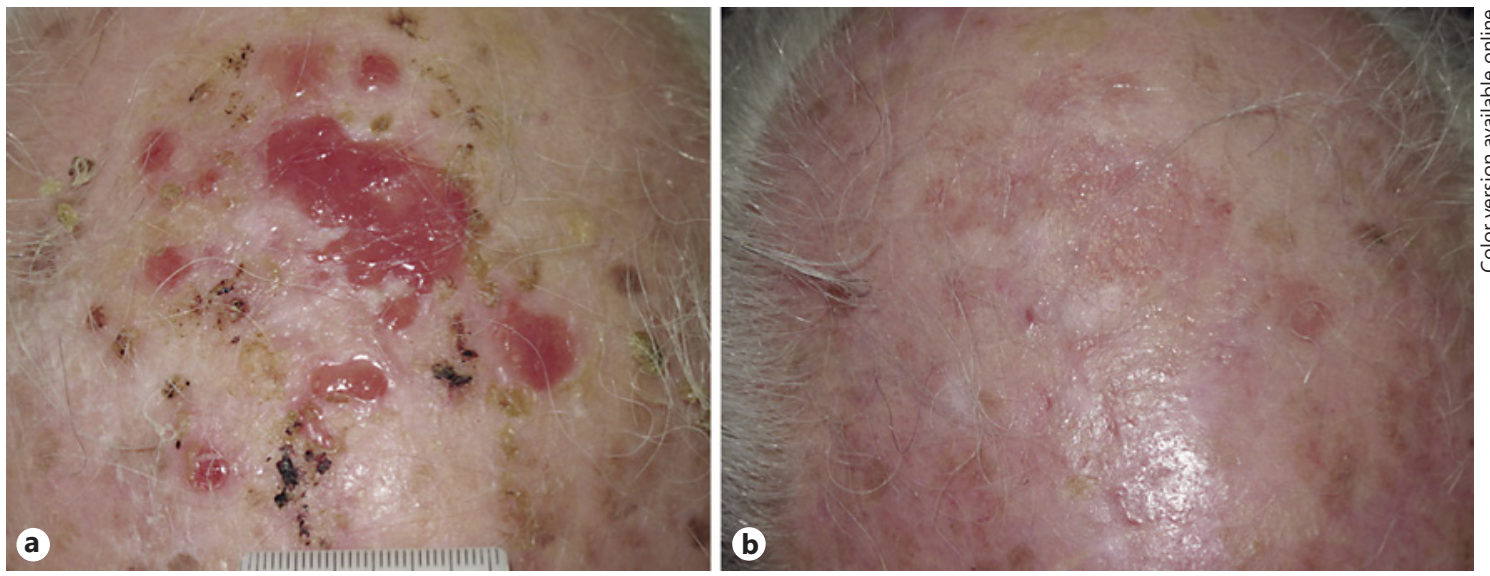

Fig. 3. Patient 2 was affected by an extensive form of EPDS with vegetant and erosive lesions of the scalp (a), showing a good result after a short course of topical clobetasol (b).

Fig. 4. Patient 4 presented with erosive lesions of the scalp (a), initially diagnosed as BCC. The patient was treated with a 2 -week course of topical clobetasol with complete resolution and residual atrophic scar (b).
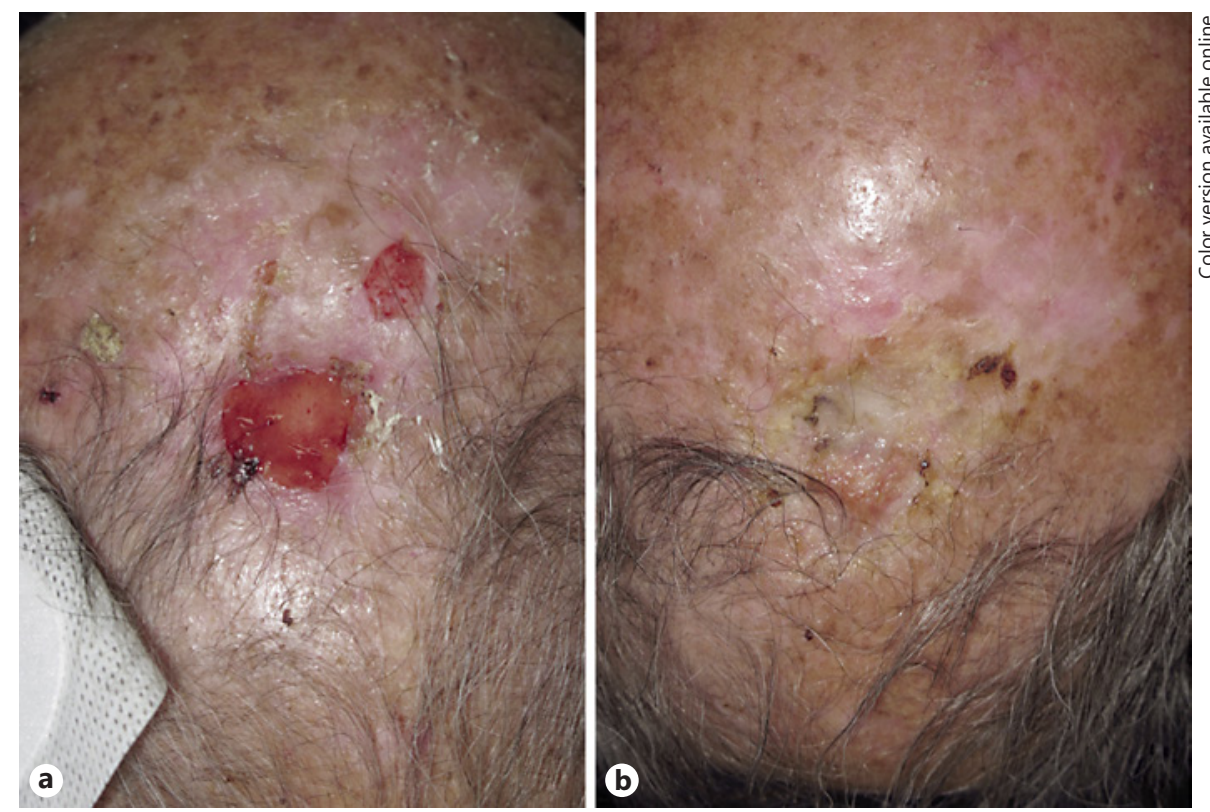

The mean age (79.6 years) in our patients was higher than that published in the literature so far. The reason for this difference is probably due to a selection bias of our case series, which exclusively included patients with an initial wrong diagnosis. As listed above, all patients were previously diagnosed with skin cancer, which is definitely more common in the elderly. Concerning clinical features, all the patients presented with nonspecific findings that are often seen in EPDS, including erosions and crusts, which could be confusing factors orienting the diagnosis towards skin malignancy rather than EPDS.

Erosive Pustular Dermatosis of the Scalp: Why Do We Miss It?
Recently, trichoscopy of EPDS has been described by Starace et al. [3] and some of the reported findings are shared by our cases. In particular, absence of follicular ostia, dilated vessels, and perifollicular serous crusts were seen in our series. Although trichoscopy may be helpful, it is usually not enough to exclude skin malignancy, in particular poorly differentiated BCC and SCC $[4,5]$. The absence of some specific dermoscopic findings, including arborizing vessels and pigmented ovoid nests (specific clues for BCC) and polymorphous vessels and white areas (specific clues for SCC), could also be helpful for differential diagnosis. Dermoscopy is usually highly supportive 
Table 2. Differential diagnosis of EPDS

\begin{tabular}{|c|c|c|c|}
\hline Diagnosis & Clinical features & Dermoscopy & Histopathology \\
\hline EPDS & $\begin{array}{l}\text { Pustules, erosions, and crusts; } \\
\text { balding scalp; chronic course }\end{array}$ & $\begin{array}{l}\text { Absence of follicular ostia, } \\
\text { dilated vessels, and } \\
\text { perifollicular serous crusts }\end{array}$ & $\begin{array}{l}\text { Aspecific; atrophic } \\
\text { epidermis and chronic } \\
\text { inflammation consisting of } \\
\text { lymphocytes, neutrophils, } \\
\text { and occasional foreign body } \\
\text { giant cells }\end{array}$ \\
\hline SCC & $\begin{array}{l}\text { Infiltrated papule/nodule, ulcer, } \\
\text { or plaque; usually single on } \\
\text { photodamaged scalp; fast } \\
\text { growing; often associated with } \\
\text { AKs }\end{array}$ & $\begin{array}{l}\text { Polymorphous vessels and } \\
\text { white areas; ulceration }\end{array}$ & $\begin{array}{l}\text { Proliferation of atypical } \\
\text { keratinocytes invading the } \\
\text { dermis and sometimes } \\
\text { deeper tissues }\end{array}$ \\
\hline BCC & $\begin{array}{l}\text { Red or pigmented papule/ } \\
\text { nodule; sometimes ulcerated; } \\
\text { slow growing }\end{array}$ & $\begin{array}{l}\text { Arborizing vessels and } \\
\text { pigmented ovoid nests; } \\
\text { erosions and ulceration }\end{array}$ & $\begin{array}{l}\text { Proliferation of basaloid } \\
\text { cells with characteristic } \\
\text { marginal palisade of tumor } \\
\text { cells and well-organized } \\
\text { stroma }\end{array}$ \\
\hline Eczema & $\begin{array}{l}\text { Itchy patches covered by fine } \\
\text { yellow crusting; history of } \\
\text { eczema elsewhere }\end{array}$ & Yellow serous crusting & $\begin{array}{l}\text { Spongiosis, variable } \\
\text { acanthosis, and } \\
\text { hyperkeratosis; } \\
\text { lymphohistiocytic infiltrate }\end{array}$ \\
\hline $\begin{array}{l}\text { Cicatricial } \\
\text { pemphigoid }\end{array}$ & $\begin{array}{l}\text { Preferentially affecting ocular } \\
\text { and genital mucosae; scalp } \\
\text { affected in } 10 \% \text { of cases } \\
\text { (Brunsting-Perry); plaque, } \\
\text { erosions, milia, and scarring } \\
\text { alopecia }\end{array}$ & Aspecific & $\begin{array}{l}\text { Similar to bullous } \\
\text { pemphigoid with } \\
\text { subepidermal blisters }\end{array}$ \\
\hline $\begin{array}{l}\text { Pustular } \\
\text { psoriasis }\end{array}$ & $\begin{array}{l}\text { Often associated with pustular } \\
\text { psoriasis elsewhere on the body } \\
\text { surface }\end{array}$ & $\begin{array}{l}\text { Pustules, dotted vessels, } \\
\text { scales }\end{array}$ & $\begin{array}{l}\text { Intense inflammation with } \\
\text { neutrophil-filled spongiform } \\
\text { pustules }\end{array}$ \\
\hline
\end{tabular}

EPDS, erosive pustular dermatosis of the scalp; SCC, squamous cell carcinoma; BCC, basal cell carcinoma; AK, actinic keratosis.

for the diagnosis of AKs, but the presence of diffuse scaling and crusting is a confounding clue present in both multiple AKs and EPDS. Moreover, EPDS and multiple AKs may coexist in the same patient, given the actinic damage which underlies both conditions.

The main problem with a missed diagnosis of EPDS is the wrong treatment consequently prescribed to the patients, including imiquimod, 5-fluorouracil, or cryotherapy, which are well-known inducing factors of EPDS.

In conclusion, our case series shows how difficult the differential diagnosis of EPDS sometimes is, since it shares common clinical features with other common cutaneous diseases, such as skin cancer. Clinical and trichoscopic features are not yet completely known, but they should guide the clinician toward a better differential diagnosis, especially when confounding features are present.

\section{Key Message}

Erosive pustular dermatosis of the scalp may be easily misdiagnosed.

\section{Disclosure Statement}

The authors have no conflicts of interest to declare. There was no funding received for this study. 


\section{References}

Erosive Pustular Dermatosis of the Scalp: Why Do We Miss It?
1 Burton JL. Case for diagnosis. Pustular dermatosis of scalp. Br J Dermatol. 1977 Jul; 97(Suppl 15):67-9.

2 Brouard MC, Prins C, Chavaz P, Saurat JH, Borradori L. Erosive pustular dermatosis of the leg: report of three cases. Br J Dermatol. 2002 Oct;147(4):765-9.

3 Starace M, Loi C, Bruni F, Alessandrini A, Misciali C, Patrizi A, et al. Erosive pustular dermatosis of the scalp: Clinical, trichoscopic, and histopathologic features of 20 cases. J Am Acad Dermatol. 2017 Jun;76(6):1109-1114. e2.

4 Russo T, Piccolo V, Lallas A, Giacomel J, Moscarella E, Alfano R, et al. Dermoscopy of Malignant Skin Tumours: What's New? Dermatology. 2017;233(1):64-73.

5 Russo T, Piccolo V, Lallas A, Argenziano G. Recent advances in dermoscopy. F1000Res. 2016 Feb;5:F1000 Faculty Rev-184. 